\title{
Long-Term Results of Surgical Repair of Bile Duct Injuries Following Laparoscopic Cholecystectomy
}

\author{
Ghofrane Talbi ${ }^{1}$, Wael Ferjaoui ${ }^{1}{ }^{*}$, Mohamed Hajri $^{1}$, Houssem eddine Smati ${ }^{1}$, Sahir Omrani ${ }^{1}$, \\ Dhouha Bacha ${ }^{2}$, Rached Bayar ${ }^{1}$, Lasaad Gharbi ${ }^{1}$, Mohamed tahar Khafallah ${ }^{1}$
}

*Corresponding author:

Wael Ferjaoui, MD

Department of General Surgery

Mongi Slim University Hospital

Faculty of medicine of Tunis

Tel: +21652430099

E-mail: farjaouiwael4@gmail.com

https://orcid.org/0000-0002-4279-9370

Received: 29.04 .2020

Accepted: 20.07.2020

$\overline{\text { Copyright } \odot \text { Celsius Publishing House }}$ www.sgo-iasgo.com
'Department of General Surgery, Mongi Slim University Hospital, Faculty of medicine of Tunis ${ }^{2}$ Department of Pathology, Mongi Slim University Hospital, Faculty of medicine of Tunis

\section{ABSTRACT}

Background: The iatrogenic injury of the bile ducts is a serious accident of laparoscopic cholecystectomy. Its management is multidisciplinary. The aim of our work was to elucidate the factors influencing the long-term results after biliary repair.

Methods: A retrospective, analytical and descriptive study was carried out on a series of 44 cases of biliary injuries repaired over a period of 14 years.

Results: The injury was discovered intraoperatively in 18 cases, in early postoperative period in 20 cases and in late postoperative period in 6 cases. In total, there were 24 lesions classified D, five lesions (E1), five lesions (E2), five lesions (E3), four lesions (E4) and a lesion (E5). Immediate repair was performed on 16 patients: 9 repairs over T-tube, 5 hepatico-jejunal anastomosis, 1 end-to-end biliary anastomosis and one patient had bilioduodenal anastomosis. Early repair was performed on 8 patients: 7 patients had a repair of the common bile duct over T-tube and only 1 patient had an hepatico-jejunal anastomosis. 20 patients were repaired late by hepatico-jejunal anastomosis. Hepatic resection has been reported in 4 of our patients. The overall mortality of biliary repairs was $9 \%$ and the overall morbidity was $18 \% .13$ patients presented biliary stricture. The factors influencing long-term outcomes were: Age $(p=0.023)$, absence of cholangiogram at repair $(p=0.04)$ and immediate repairs $(p=0.048)$. Late repair was associated with good long-term results.

Conclusion: The iatrogenic wound of the bile ducts is a frightening accident of laparoscopic cholecystectomy. Its care is multidisciplinary but not yet consensual.

Key words: Biliary tract, Cholecystectomy, Laparoscopy, Morbidity, Stricture

\section{INTRODUCTION}

Cholecystectomy is one of the most performed procedures in visceral surgery (1). With the generalization of laparoscopic cholecystectomy which becomes the gold standard for symptomatic cholecystolithiasis (1), the rate of iatrogenic bile duct injury has increased during the last decades by up to $3 \%$ (2). Several injuries may occur. Long-term complications arising after these injuries include biliary stenosis, cholangitis and hepatic atrophy. Later, fibrosis, secondary biliary cirrhosis and portal hypertension may develop. Many classifications for severity of bile duct injuries have been described. Strasberg classification is able to classify all types of injury and is used widely in describing bile duct injuries following laparoscopic cholecystectomy. The Management of these complications often consists 
in surgery but may require an endoscopic and/ or radiological approach. These injuries are associated with a high rate of morbidity and mortality with an impact on the quality of life of patients (3). The aim of our work was to evaluate long-term results after biliary repair and to determine the factors influencing their prognosis.

\section{METHODS}

This is a retrospective study of bile duct injuries following laparoscopic cholecystectomy.

We included in our study all patients who underwent laparoscopic cholecystectomy for symptomatic cholecystolithiasis as well as for chronic and acute cholecystitis. Exclusion criteria were bile duct injuries during hepatic surgery, Choledocotomies during treatment of common bile duct stones, all open cholecystectomies and fewer than 3 years of follow up. Data were analyzed by frequency tables and cross tabulation as found appropriate by the statistics program IBM SPSS version 21 . The $95 \%$ confidence level is used in our work. The significance level is set at 0.05 or $5 \%$. The comparison of continuous variables was carried out using the Mann-Whitney test. The comparison of categorical variables was carried out using a chi-square test. Overall survival (OS) and recurrence-free survival (RFS) were determined by Kaplan-Meier method. The study of prognostic factors of survival was carried out by calculating the Odds ratio. Different types of repair used in our study were divided into 3 periods: an immediate repair ( 0 to 72 hours), an early repair ( 72 hours to 6 weeks) and a late repair (more than 6 weeks). The management of iatrogenic bile duct injuries in our study consists of endoscopic, radiological and surgical treatment. Failure of the biliary repair was diagnosed by the appearance of biliary symptoms, such as jaundice, recurrent cholangitis and secondary biliary cirrhosis. This failure was observed within a variable delay.

\section{RESULTATS}

During the study period, 44 patients with 7 men and 37 women were included in the database. The median age was 50 (range 26-78) years. Cholecystectomy was performed for symptomatic cholecystolithiasis in $63 \%$ of the cases. It was performed for acute cholecystitis in $31.6 \%$ of cases and for biliary peritonitis in one case. Injuries were discovered intraoperatively in 18 cases $(40 \%)$ due to the presence of bile leak in the operating field or following an intraoperative cholangiography. In 20 cases, the injury was discovered within 3 weeks. In this group, biliary peritonitis was the major symptom in 10 cases $(50 \%)$, whereas $20 \%$ had bile leak, 3 cases had jaundice, 2 cases had biloma and 1 case had an acute angiocholitis. In 6 cases (13\%), the injury was discovered after 3 weeks. Symptoms were jaundice in 3 cases and repeated acute angiocholitis in 3 cases. Lesions were classified according to the Strasberg classification. In total, there were 24 lesions (54\%) classified D, 5 classified E1 (11\%), 5 classified E2 (11\%), 5 classified E3 (11\%), 4 classified E4 (9\%) and one classified E5 (2\%) (table 1). In our series 2 patients had lesions of the right hepatic artery which were associated with bile duct injuries. An external biliary drainage was performed in 2 patients, an endoscopic treatment in 2 patients, percutaneous drainage in 2 patients and surgical drainage in 12 patients. Intraoperative cholangiography was performed in 5 cases. It showed leakage of the contrast agent due to a lateral wound of the VBP in 4 cases and stenosis at the level of convergence in 1 case. Abdominal ultrasound was performed on 11 patients. It objectified an intraperitoneal effusion in 3 cases, biloma in 1 case and dilatation of bile ducts in 7 cases. Abdominal computed tomography was indicated in 10 patients and objectified an intraperitoneal effusion in 5 patients, collection under the liver in two patients, dilatation of bile ducts in 2 patients and image of hypoperfusion of the right liver due to lesion of the right hepatic artery in 2 patients. A bili-MRI was

Table 1 - Demographic data of 44 patients

\begin{tabular}{lc}
\hline Characteristic & Number \\
\hline Sex & \\
M & 7 \\
F & 37 \\
\hline Age, median (range) & $50(12-80)$ \\
\hdashline Patient presentation & \\
Biloma & 2 \\
Biliary fistula & 4 \\
Biliary peritonitis & 10 \\
Jaundice & 6 \\
Acute cholangitis & 4 \\
\hline Time of bile duct injuries presentation & \\
At laparoscopic cholecystectomy & 18 \\
Early Postoperative & 20 \\
Late Postoperative & 6 \\
Type of lesion according to the Strasberg Classification & \\
D & 24 \\
E1 & 5 \\
E2 & 5 \\
E3 & 5 \\
E4 & 4 \\
E5 & 1 \\
\hline
\end{tabular}


indicated in 21 patients.

Immediate repair was performed in 16 patients: 9 patients had drainage by Kehr's $T$ tube for lesions classified as Strasberg D, 5 had bilio-jejuno anastomosis, 1 patient had bilio-biliary anastomosis and 1 patient had bilio-duodenal anastomosis. Early repair was carried out in 8 patients: 7 patients had drainage by Kehr's T tube and 1 patient had bilio-jejuno anastomosis. 20 patients were repaired late with a bilio-jejuno anastomosis (table 2). Hepatic resection was indicated in 4 patients for liver atrophy.

The overall mortality rate was $9 \%$ and the overall morbidity rate was $18 \%$. The average follow-up was 6 years with extremes ranging from 3 to 15 years. During the follow-up, 13 patients presented a failure of the biliary repair (32\%) observed within times varying from 9 months to 15 years with a median of 24 months. The factors that influenced the long-term results in our series were: age $(p=0,023)$, absence of cholangiogram during repair $(p=0,04)$ and immediate repair $(p=0$, 048) (table 3).

\section{DISCUSSION}

The problem of iatrogenic bile duct injuries arose from the first open cholecystectomies, as demonstrated by the work of Von Riedel carried out 6 years after the first cholecystectomy. Their incidence was between 0 and $0.5 \%$ (1). After the generalization of laparoscopic cholecystectomy, the incidence of biliary injuries increased rapidly and reached 1 to $2.8 \%(1,2)$. The average age found in several studies was between 46 and 54 years $(4,5)$. In our series the average age was 50 years. It is more frequent in women with a sex ratio close to 0.25 (5). In our series the sex ratio was 0.18 . The rate of injuries was $0.36 \%$ in acute cholecystitis and $3 \%$ in chronic cholecystitis (6). In our series, $31.6 \%$ of the iatrogenic lesions of the bile ducts occurred after cholecystectomies for acute cholecystitis. Locoregional

Table 2 - Type of repair by timing

\begin{tabular}{lc}
\hline Characteristic & Number \\
\hline immediate repair (0 to 72 hours) & \\
drainage by Kehr's T tube & 9 \\
bilio-jejuno anastomosis & 5 \\
bilio-biliary anastomosis & 1 \\
bilio-duodenal anastomosis & 1 \\
\hline Early repair (72 hours to 6 weeks) & \\
$\quad$ drainage by Kehr's T tube & 7 \\
bilio-jejuno anastomosis & 1 \\
\hdashline Late repair (more than 6 weeks) & \\
bilio-jejuno anastomosis & 20 \\
\hline
\end{tabular}

conditions such as pediculitis, acute pancreatitis, obesity and intraoperative hemorrhage are confirmed as risk factors $(4,5)$. Anatomical variations increase bile duct injuries (7) especially those related to an anatomical variation of the cystic duct. The most frequent of these anatomical variations is the presence of an accessory bile duct which represents 15 to $50 \%$ of cases. Bile duct injuries can be discovered intraoperatively to several years after cholecystectomy. Intraoperatively, it can be manifested by the leakage of bile in the operating field, by the presence of a double biliary stump or on an intraoperative cholangiography. In our study, the biliary wound was discovered intraoperatively in 18 cases with a rate of $40 \%$. Otherwise, bile duct injuries were recognized late; several weeks or months after cholecystectomy. In our study we set 6 weeks as an early period and $>6$ weeks as a late period. Vascular lesions are frequently observed in proximal biliary injuries with rates varying between 35 and $40 \%$ (8). Lesion of the right branch of the hepatic artery is the most common lesion and may be associated with a portal lesion (9). The management of bile duct injuries depends on several factors and many therapeutic attitudes are proposed.

Surgical external bile drainage is indicated when biliary repair is difficult or doomed to failure (10). These situations are complex injuries, necrosis of bile ducts, Local inflammation and lack of experience of the surgeon. This type of drainage involves intubating the visible bile ducts or fistula through a $\mathrm{T}$ tube and externalizing it to the skin. It is necessary to associate a large drainage of the subhepatic region (11). Percutaneous drainage carried out under imaging control aims to drain the bile ducts and bilomas (12). This type of drainage is indicated in case of (13): Complex injuries close to biliary convergence, type E2 to E5 of the Strasbourg classification, injuries of segmental or sectoral bile ducts Type B and C of the Strasberg classification, failure of endoscopic treatment. Endoscopic treatment is only indicated when the bile ducts upstream of the stenosis are clouded with an intrahepatic cholangiogram (14). It finds its place in the treatment of fistulas and biliary stenoses post cholecystectomy (15). In case of stenosis,

Table 3 - Factors that influenced the long-term results in our series

\begin{tabular}{lccc}
\hline Predictor & $\mathbf{p}$ & $\mathbf{O R}$ & IC à 95\% \\
\hline Age & 0,023 & 9,62 & $1,36-28,8$ \\
\hline The absence of cholangiogram & 0.04 & 1,97 & $1,22-7,4$ \\
\hline Immediate repair & 0.048 & 1.85 & $1.30-6.5$ \\
\hline
\end{tabular}




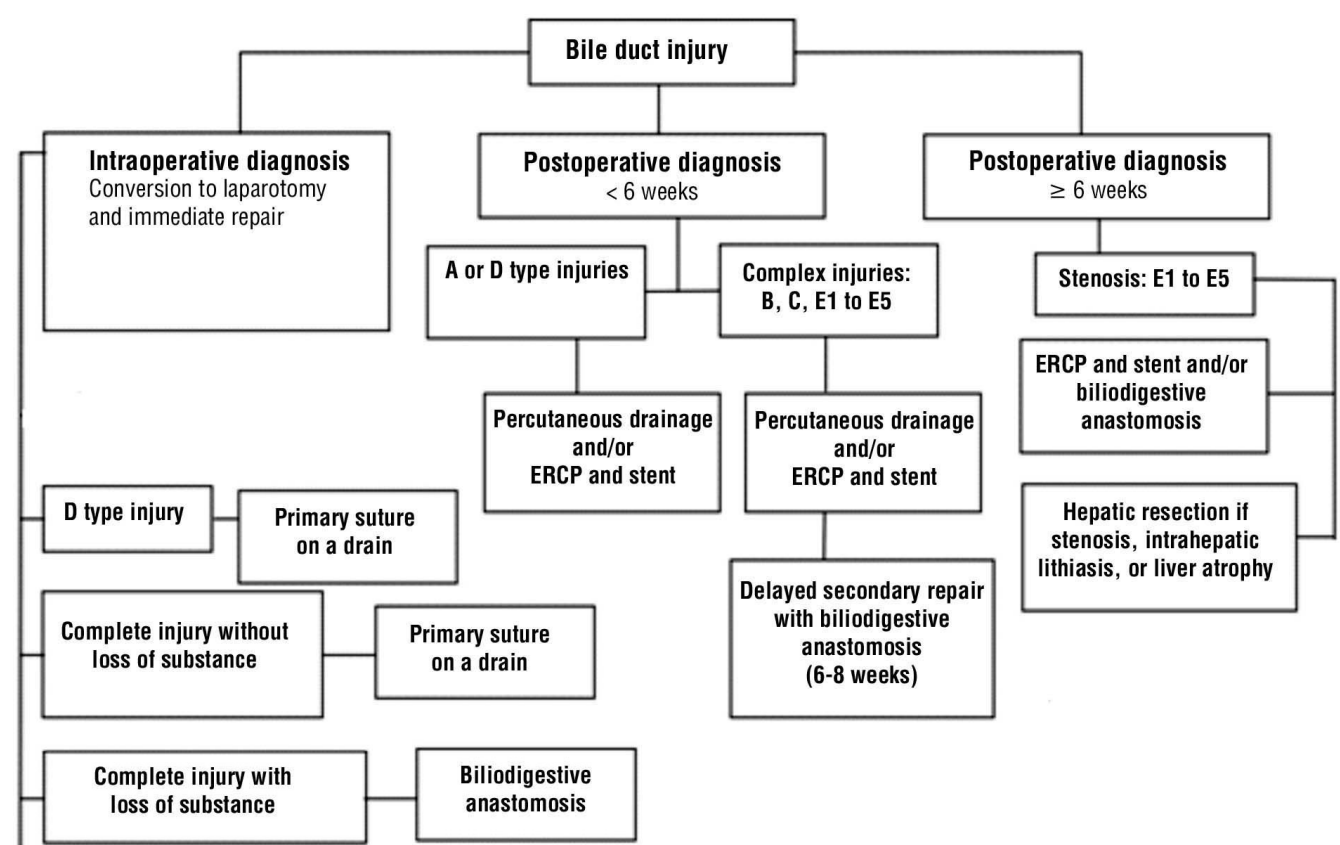

the treatment consists in dilating and calibrating it or not with prosthesis. In case of fistula: A minimal bile leak (flow $<200 \mathrm{ml} / 24 \mathrm{~h}$ ) makes suspect a minor wound. In this case an endoscopic sphincterotomy may be sufficient (efficiency from 89 to $100 \%$ ). Endoscopic biliary implants are indicated for high-flow fistulas with loss of substance and should be combined with percutaneous drainage of a biloma or collection (16). In our study, endoscopic treatment was initiated in 4 patients. In 2 patients, it was indicated for a biliary fistula. In 2 cases, the placement of a biliary prosthesis was indicated for anastomotic stenosis. The goal of surgical repair is the restoration of bile permeability. Biliary repair is only done after having made an exhaustive lesion evaluation. The timing of the repair depends on the local condition, the nature and location of the lesions and the general condition of the patient. The strictures stabilize within 6 to 8 weeks. In the case where it is of ischemic origin this period is extended to 3 months. These delays make it possible to have fixed lesions and to make repairs on dilated bile ducts (15.16). Stenosis by mechanical obstacle (Clip, Ligature) must be treated immediately without waiting for these delays. Indeed, immediate repair by an expert surgeon gives good short and long term results. The presence of a septic focus, the absence of biliary mapping and the

deterioration of the patient's general and nutritional status should delay repair (17). Several repair techniques have been proposed. Biliary drainage via Kehr's T-tube is the most common repair technique during immediate repairs (18). In our study, this technique was performed in 13 patients, including 7 during an immediate repair. Long-term follow-up was complicated by stenosis in 4 cases. It is indicated for lateral wounds of the bile ducts with or without a little defect. Bilio-biliary anastomosis is the first repair technique described. It is indicated for the complete sections of the CBD. It is only performed when the section is clear without significant loss of substance, bile ducts of the same caliber and well vascularized. This technique is at high risk of longterm stenosis and requires endoscopic management later. In our study, it was carried out in a single patient who developed biliary stenosis at 1 year. He had an endoscopic prosthesis and a late secondary repair by hepatico-jejunal anastomosis (Roux $Y$ ) is the only technique indicated in the case of complex injuries and in the event of loss of substance. It is indicated for immediate or late repairs. However, early repairs by hepatico-jejunal anastomosis are associated with bad results (19). Hepatic resection is indicated in case of lesion touching the artery and the portal vein with hepatic necrosis, if the intrahepatic canals of a lobe or 
segment are affected, making repair impossible, in case of stenosis of a hepatic or sectoral canal with hepatic atrophy symptomatic of recurrent angiocholites (20). Liver transplantation remains the only treatment for biliary cirrhosis with signs of hepatocellular insufficiency (21). It remains a rare indication in the management of biliary wounds. The largest series was reported by De Santibanes et al (14) who collected 16 liver transplants following a biliary injury including 13 after cholecystectomy. The mortality rate after biliary repair varies according to recent studies from $3.1 \%$ to $5 \%$ (22). These same studies have shown that repairs carried out early in the postoperative period with a local inflammatory condition increased the mortality rate.

In our series, the overall mortality was $9 \%$. The morbidity rate reported by the various studies varies between $19 \%$ and $30 \%$ (23). The most common complications after biliary repair are anastomotic fistulas, collections and postoperative angiocholitis (24). The success of a biliary repair is judged on the absence of biliary symptoms within 3 to 5 years following the surgical procedure (25). Stenosis occurs in $60 \%$ of cases within 3 years after biliary repair and $90 \%$ within 7 years. Some authors have described strictures at 10 years (26). The success rate of biliary repairs varies from 70 to $93 \%$ in specialized centers (27). The rate of anastomotic stenosis described in the literature varied from 5 to $36 \%$.

\section{CONCLUSION}

The iatrogenic wound of the bile ducts is a frightening accident of laparoscopic cholecystectomy. Its care is multidisciplinary but not yet consensual with very variable long-term results depending on the care arrangements and the teams.

\section{Ethical approval}

The authors have obtained institutional approval and whether they have complied with the terms of the Helsinki Agreement.

\section{Conflict of interest: No conflict.}

\section{REFERENCES}

1. Renz BW, Bösch F, Angele MK. Bile Duct Injury after Cholecystectomy: Surgical Therapy. Visc Med. 2017/05/26. 2017; 33(3):184-90.

2. Jabłońska B, Lampe P. latrogenic bile duct injuries: etiology, diagnosis and management. World J Gastroenterol. 2009;15(33): 4097-104

3. Ou ZB, Li SW, Liu CA, Tu B, Wu CX, Ding X, et al. Prevention of common bile duct injury during laparoscopic cholecystectomy. Hepatobiliary Pancreat Dis Int. 2009;8:414-7.

4. Habib FA, Kolachalam RB, Khilnani R. Role of laparoscopic cholecys- tectomy in the management of gangrenous cholecystitis. Am J Surg. 2001;181:71-5

5. Giger UF, Michel JM, Opitz I, Inderbitzin DT, Kocher T, Krähenbühl L et al. Swiss Association of Laparoscopic and Thoracoscopic Surgery (SALTS) Study Group. Risk factors for perioperative complications in patients undergoing laparoscopic cholecystectomy: analysis of 22,953 consecutive cases from the Swiss Association of Laparoscopic and Thoracoscopic Surgery database. J Am Coll Surg. 2006;203(5):723-8.

6. Adamsen S, Hansen $\mathrm{OH}$, Funch-Jensen P, Schulze S, Stage JG, Wara P. Bile duct injury during laparoscopic cholecystectomy: a prospective nationwide series. J Am Coll Surg.1997:184(6):571-8.

7. Stewart L, Way LW. Laparoscopic bile duct injuries: timing of surgical repair does not influence success rate. A multivariate analysis of factors influencing surgical outcomes. HPB. 2009;11(6):516-22.

8. Mercado MÁ, Chan C, Orozco H, Villalta JM, Barajas-Olivas A, Eraña $J$, et al. Long-term evaluation of biliary reconstruction after partial resection of segments IV and V in iatrogenic injuries. J Gastrointest Surg. 2006;10(1):77-82

9. Ferguson CM, Rattner DW, Warshaw AL. Bile duct injury in laparoscopic cholecystectomy. Surg Laparosc Endosc Percutan Tech. 1992; 2:1-7.

10. Thomson BNJ, Parks RW, Madhavan KK, Wigmore SJ, Garden OJ. Early specialist repair of biliary injury. Br J Surg. 2006;93(2):216-20.

11. Schmidt SC, Langrehr JM, Hintze RE, Neuhaus $P$. Long-term results and risk factors influencing outcome of major bile duct injuries following cholecystectomy. Br J Surg. 2005;92(1):76-82.

12. Mercado MA, Domínguez I. Classification and management of bile duct injuries. World J Gastrointest Surg. 27 avr 2011;3(4):43-8.

13. Slater K, Strong RW, Wall DR, Lynch SV. latrogenic bile duct injury: the scourge of laparoscopic cholecystectomy. ANZ J Surg. 2002; 72(2):83-8

14. Santibánes E, Ardiles V Pekolj J. Complex bile duct injuries: management. HPB.2008;10(1) :4-12.

15. Bismuth $\mathrm{H}$, Majno PE. Biliary strictures: classification based on the principles of surgical treatment. World J Surg. 2001;25(10):1241-4.

16. Perera MTP, Silva MA, Hegab B. Specialist early and immediate repair of post-laparoscopic cholecystectomy bile duct injuries is associated with an improved long-term outcome. Ann Surg. 2011; 253(3):553-60.

17. Pesce A, Palmucci S, La Greca G, Puleo S. latrogenic bile duct injury: impact and management challenges. Clin Exp Gastroenterol. 2019; 12:121-128

18. Ragozzino A, De Ritis R, Mosca A, laccarino V, Imbriaco M. Value of MR cholangiography in patients with iatrogenic bile duct injury after cholecystectomy. Am J Roentgenol. 2004;183(6):1567-72.

19. Bergmann JJ, Burgmeister I, Bruno MJ, RauwsEA, Gouma DJ, Tytgat GN, et al. Long-term follow-up after biliary stent placement for postoperative bile duct stenosis. Gastrointest Endosc. 2001;54: 154-61

20. $\mathrm{Ng} J J, K o w$ AWC, Pedicled omental patch as a bridging procedure for iatrogenic bile duct injury. World J Gastroenterol. 2017;23(36):67416746 .

21. Nordin A, Halme L, Mäkisalo $\mathrm{H}$, Isoniemi $\mathrm{H}$, Höckerstedt $\mathrm{K}$ Management and outcome of major bile duct injuries after laparoscopic cholecystectomy: from therapeutic endoscopy to liver transplantation. Liver Transpl. 2002;8(11):1036-43.

22. Aziz AM, Shoreem H, Sallam A, Al-warraky M, Sadek A, Osman M. latrogenic bile duct injury: A retrospective analysis of short-and long-term outcomes after surgical repair. Saudi Surg J. 2016;4(2):61.

23. Schmidt SC, Settmacher U, Langrehr JM, Neuhaus P. Management and outcome of patients with combined bile duct and hepatic arterial injuries after laparoscopic cholecystectomy. Surgery. 2004; 135(6):613-8

24. Iannelli A, Paineau J, Hamy A, Schneck AS, Schaaf C, Gugenheim J. Primary versus delayed repair for bile duct injuries sustained during cholecystectomy: results of a survey of the Association Française de Chirurgie. HPB. 2013;15(8):611-6.

25. De Santibañes E, Ardiles V, Gadano A, Palavecino M, Pekolj J, Ciardullo M. Liver transplantation: the last measure in the treatment of bile duct injuries. World J Surg. 2008;32(8):1714-21.

26. Alves A, Farges O, Nicolet J, Watrin T, Sauvanet A, Belghiti J. Incidence and consequence of an hepatic artery injury in patients with postcholecystectomy bile duct strictures. Ann Surg. 2003;238(1):93-6.

27. Cozzi G, Severini A, Civelli E. Percutaneous transhepatic biliary drainage in the management of postsurgical biliary leaks in patients with nondilated intrahepatic bile ducts. Cardiovasc Intervent Radiol. 2006;29(3):380-8 